\title{
A Study on the Changes of Platelet Aggregability Due to Ischemia*
}

\author{
Takemichi Kanazawa**, Masahiro Izawa**, Hirohiko KaneKo**, \\ Tsugumichi Uemura**, Yoshiyuki Konta**, Kogo OnODERA**, \\ Hirobumi Metoki***, Chusei Ninei***, Osamu Komatsu*** \\ and Yasaburo OIKE***
}

Platelet aggregability in ischemic diseases such as myocardial infarction and cerebrovascular diseases has been reported ${ }^{1-3}$ ) numerously in the past. According to these reports, the platelet aggregability is higher in patients with arteriosclerotic diseases than in healthy persons. We also had previously published ${ }^{4,5}$ ) that platelet aggregabilities increase in patients with those diseases.

To clarify the mechanisms of the increasing platelet aggregabilities in ischemic diseases, we had investigated whether ischemia, namely, lack of oxygen, increased or decreased platelet aggregability.

\section{Experimental Method}

1) Platelet aggregability

Platelet aggregabilities induced by ADP $(2 \mu \mathrm{M} /$ $l$ as final concentration), collagen $(1 \mu \mathrm{g} / \mathrm{m} l)$, and epinephrine $(1 \mu \mathrm{g} / \mathrm{m} l)$ were measured by the formal method which has been presented in our previous reports. ${ }^{4,5)}$

The aggregability was expressed in maximum platelet aggregabilities (MPA) calculated from aggregation profiles.

2) MPA before and after oxygen $\left(\mathrm{O}_{2}\right)$ inhalation

MPAs before and after $\mathrm{O}_{2}$ inhalation were estimated in 6 patients with 2 strokes, 2 old myocardial infarctions, 1 cor pulmonale and 1 hypertensive. They received $\mathrm{O}_{2}$ of $2 \mathrm{l} / \mathrm{min}$ via nasal canal for dyspnea. Their blood was drawn twice before $\mathrm{O}_{2}$ inhalation, and 60 minutes after an inhalation.

* This paper was presented at the 18 th meeting of the Japan Atherosclerosis Society in Japan in May 1986

** Second Department of Internal Medicine, Hirosaki University School of Medicine, Hirosaki, Japan

*** Reimeikyo Rehabilitation Hospital
3) MPA of venous and arterial blood

Nine $\mathrm{m} l$ of blood from the cubital vein and the femoral artery of 6 patients with 3 cerebral thrombosis, 2 ischemic heart diseases, and 1 hypertensive was drawn simultaneously into two syringes with $1 \mathrm{ml}$ of $3.8 \%$ sodium citrate. The platelet rich plasmas (PRP) ${ }^{6}$ ) of venous and arterial blood were separated and MPAs were estimated.

4) Ischemic state by ligation

The upper arms in 10 healthy subjects were ligated with systolic blood pressure plus a pressure of another $20 \mathrm{mmHg}$ for 5 minutes. Blood was drawn twice before the ligations and 5 minutes after ligations from their cubital veins in the side of their ligated arms.

5) Oxygen $\left(\mathrm{O}_{2}\right)$, nitrogen $\left(\mathrm{N}_{2}\right)$, and carbon monoxide $(\mathrm{CO})$ bubblings

The above gases were bubbled into the PRP') at the rate of two bubbles per second. The bubbling condition was crucial here because the rate over 2 bubbles per second created many bubbles in the tubes which disturbed the estimation of the platelet aggregability. The subjects were 8 healthy persons.

Therefore, a specific gas controller was used to maintain this rate. The gases were purchased from Seikagaku Industrial Company for the gas chromatography.

\section{Experimental Results}

1) The effect of $\mathrm{O}_{2}$ inhalation on MPA

Compared with MPAs before $\mathrm{O}_{2}$ inhalation of $2 \mathrm{l} / \mathrm{min}$ for 60 minutes, the MPAs induced by ADP and epinephrine were after $\mathrm{O}_{2}$ inhalation suppressed (as shown in Fig. 1). A decreasing trend was recognized after the $\mathrm{O}_{2}$ inhalation in collagen induced MPA.

2) Comparison of MPAs between venous and arterial blood

MPAs showed a higher trend in the platelet 

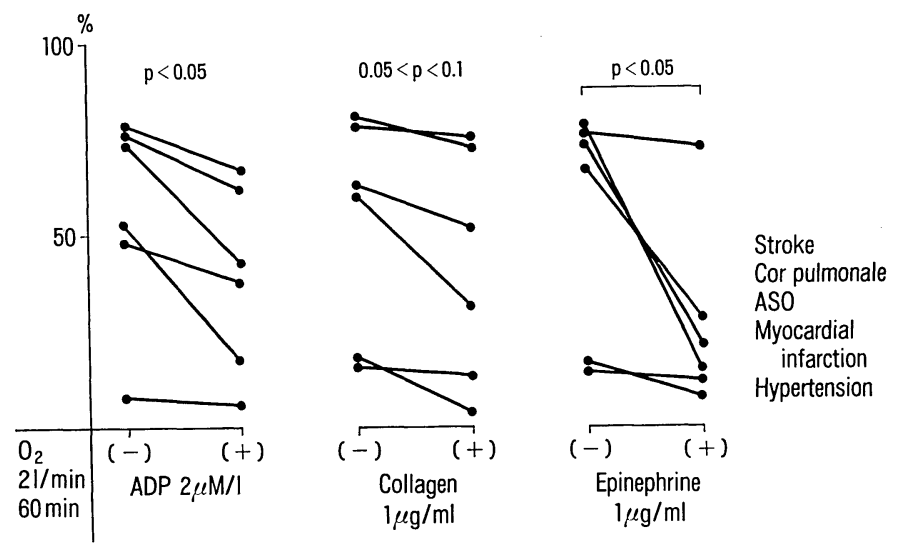

Fig. 1 The effect of $\mathrm{O}_{2}$ inhalation ( $\left.2 \mathrm{l} / \mathrm{min} 60 \mathrm{~min}\right)$ on the platelet aggregation.
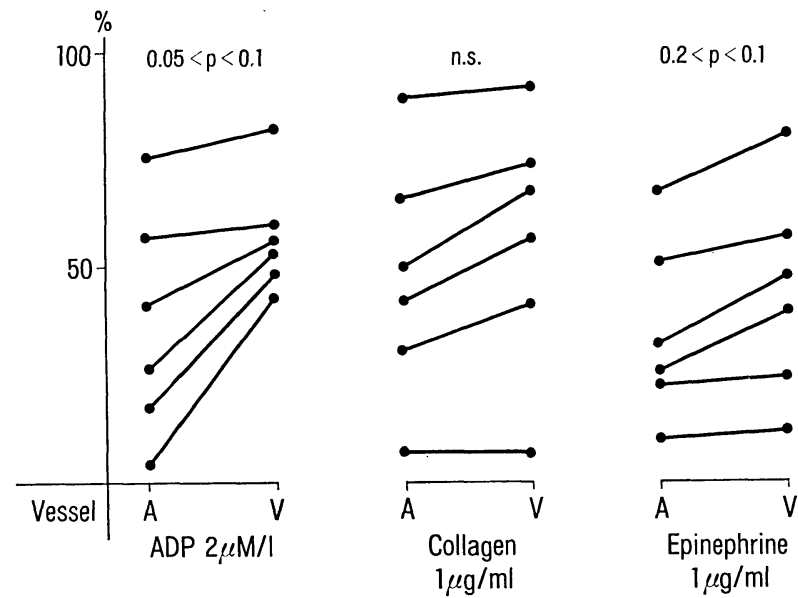

Fig. 2 Comparison of the platelet aggregation between arterial PRP and venous PRP.

aggregability in the venous blood than in the arterial bood (in the aggregants of ADP and epinephrine). But in collagen induced MPA, there were no differences (as shown in Fig. 2).

3) The influence of anoxia to MPA by ligation As shown in Fig. 3 and Table 1; ADP, collagen, and epinephrine induced MPA before ligation were clearly suppressed in post ligation. The profiles of the platelet aggregations were mentioned in Fig. 3.

4) The effects of ADP induced MPA by $\mathrm{O}_{2}$, $\mathrm{N}_{2}$, and $\mathrm{CO}$ bubblings

a) $\mathrm{O}_{2}$

As shown in Figs. 4 and 5, the MPA increased after the $30 \mathrm{sec}$ and $60 \mathrm{sec} \mathrm{O}_{2}$ bubblings. But the MPA did not show an increase after the $\mathrm{O}_{2}$ bubbl-
Table 1 Comparison of platelet aggregability between before and after ligation on arm

\begin{tabular}{rr|l|l} 
& \multicolumn{3}{c}{ Healthy Persons } \\
\hline \multicolumn{2}{c|}{ Aggregants } & \multicolumn{1}{c}{ Before (\%) } & \multicolumn{1}{c}{ After (\%) } \\
\hline ADP $1 / \mu \mathrm{M} / 1$ & $28.4 \pm 10.9$ & $16.5 \pm 11.1^{*}$ \\
& $2 \mu \mathrm{M} / \mathrm{I}$ & $69.3 \pm 18.9$ & $53.3 \pm 30.9$ \\
Collagen $0.5 \mu \mathrm{g} / \mathrm{ml}$ & $29.8 \pm 10.9$ & $18.7 \pm 7.4^{*}$ \\
$1.0 \mu \mathrm{g} / \mathrm{ml}$ & $70.6 \pm 13.0$ & $60.8 \pm 19.1$ \\
Epinephrine $1 \mu \mathrm{g} / \mathrm{ml}$ & $28.4 \pm 10.9$ & $16.5 \pm 11.1^{*}$ \\
$2 \mu \mathrm{g} / \mathrm{ml}$ & $69.3 \pm 18.9$ & $53.3 \pm 15.6$ \\
\hline
\end{tabular}

$\mathrm{N}=10, \quad{ }^{*} \mathrm{p}<0.05$, Mean \pm SD.

Left arm was ligated by the pressure with maximum blood pressure plus $20 \mathrm{mmHg}$ for 5 minutes. 
A Study on the Changes of Platelet Aggregability Due to Ischemia

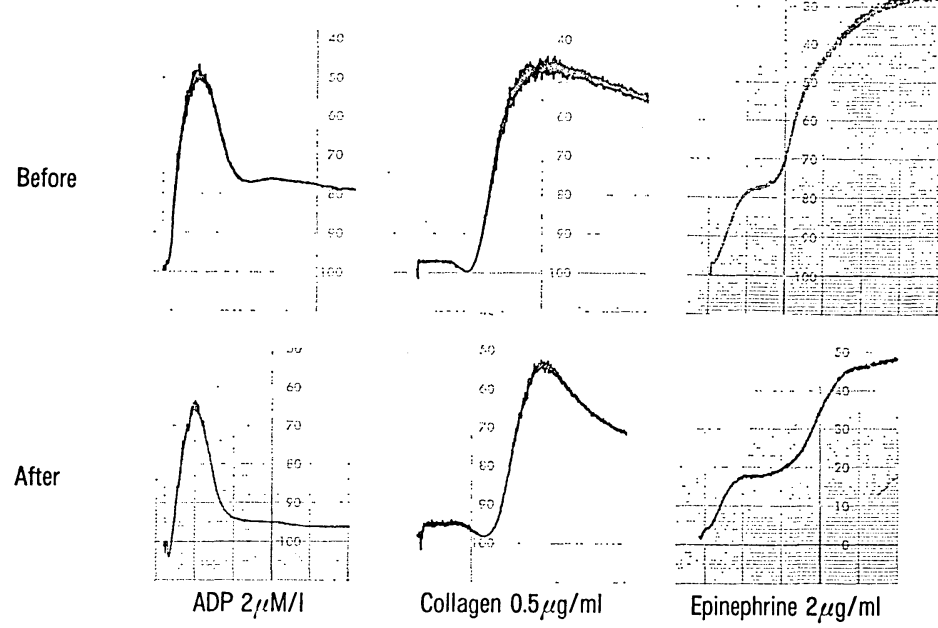

Fig. 3 Profiles of platelet aggregation by each aggregants before and after ligation on arm.
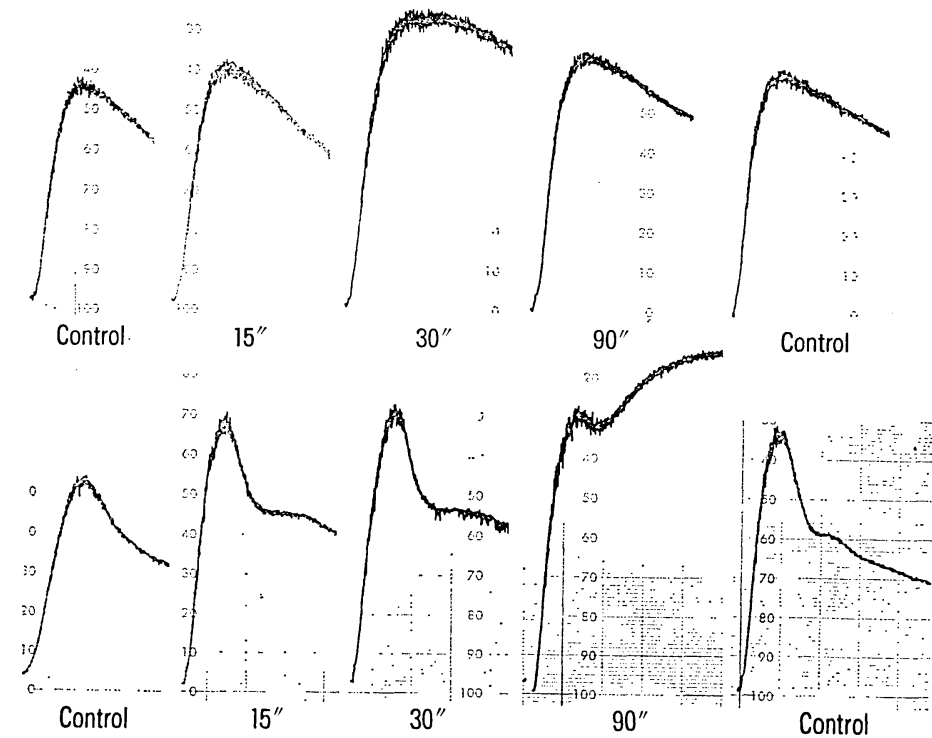

Fig. $4 \mathrm{O}_{2}$-bubbling.

ing of over 2 minutes to PRP.

b) $\mathrm{N}_{2}$

As shown in Figs. 6 and 7, the MPA did not show any clear change until after 5 minutes.

c) $\mathrm{CO}$

As shown in Figs. 8 and 9, the MPA (pre-CO bubblings) decreased tremendously after the bubblings. The MPA after the $30 \mathrm{sec} \mathrm{CO}$ bubblings were the most suppressed.

\section{Discussion}

It has been often reported ${ }^{7-10)}$ that the MPA in patients with ischemic diseases such as myocardial infarction, cerebral thrombosis, and arteriosclerosis obliterance, increases more compared to the MPA of healthy persons. We have observed ${ }^{4,5}$ ) that the MPA also increases in ischemic heart diseases and cerebrovascular diseases. Although the mechanism 


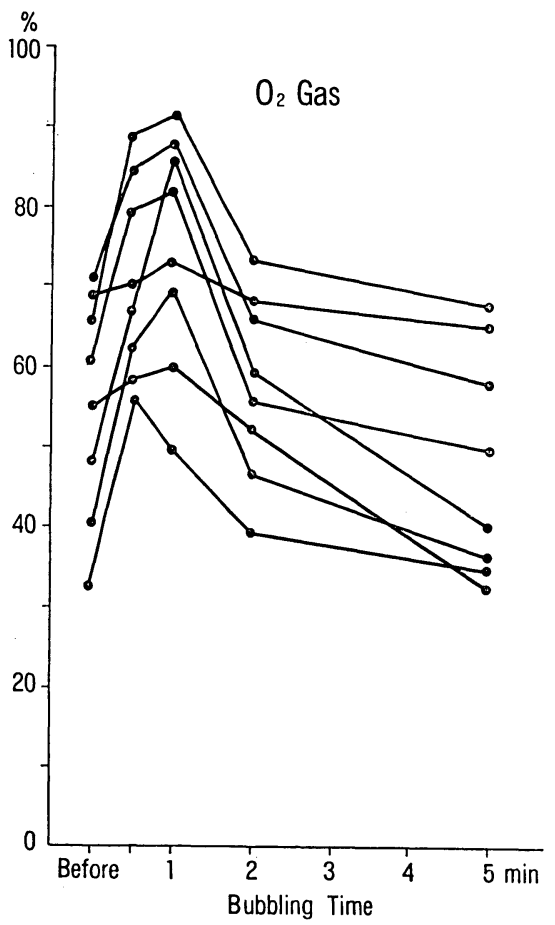

Fig. 5 The effect on ADP $(2 \mu \mathrm{M} / l)$ induced platelet aggregability by $\mathrm{O}_{2}$ gas bubbling.

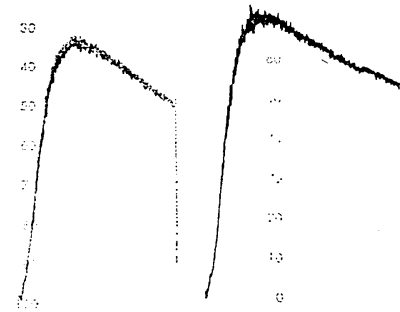

Control

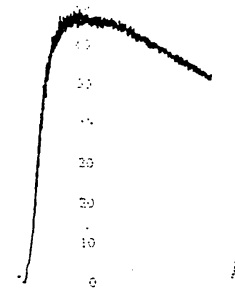

$30^{\prime \prime}$

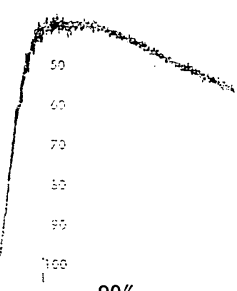

$90^{\prime \prime}$

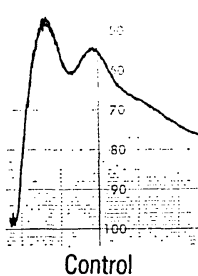

Control

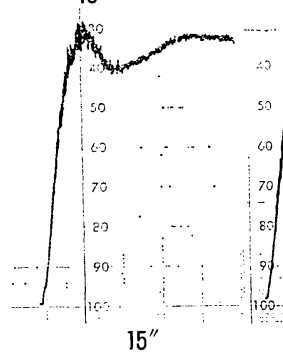

$15^{\prime \prime}$

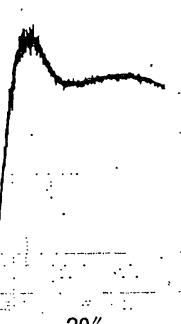

$30^{\prime \prime}$

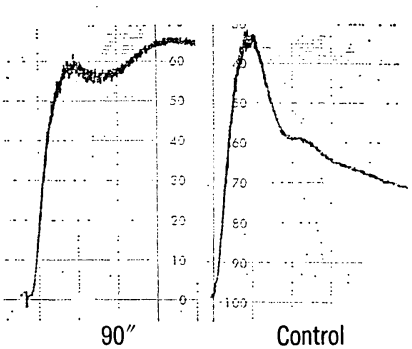

$90^{\prime \prime}$

Control

Fig. $6 \mathrm{~N}_{2}$-bubbling.

is unclear, from these results, it was presumed that the deficiency of $\mathrm{O}_{2}$ in the tissue would make the MPA increase.

Parts of the results of this experiment supports the above speculation. Namely, the MPAs in the venous blood showed a higher trend compared the MPAs in the arterial blood, and the MPAs after the $\mathrm{O}_{2}$ inhalation were suppressed compared to the 
A Study on the Changes of Platelet Aggregability Due to Ischemia

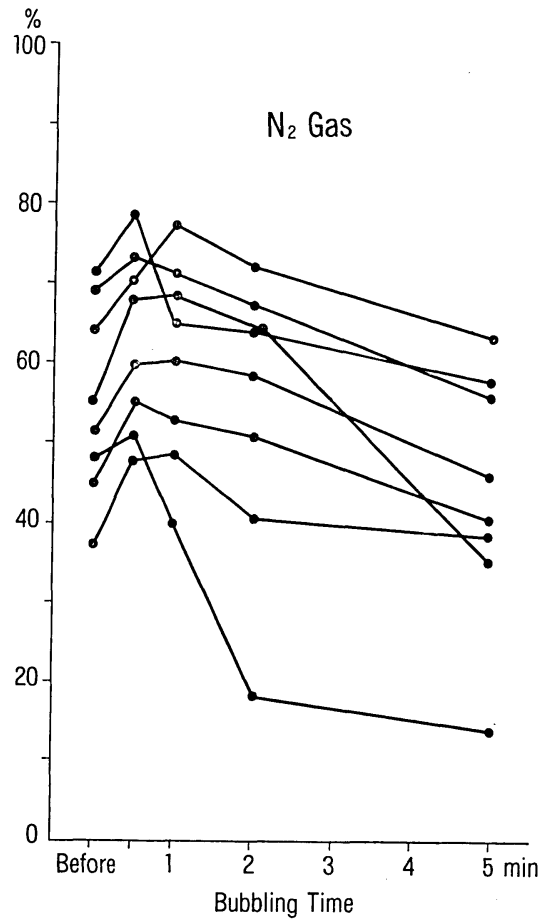

Fig. 7 The effect on ADP $(2 \mu \mathrm{M} / l)$ induced platelet aggregability by $\mathrm{N}_{2}$ gas bubbling.
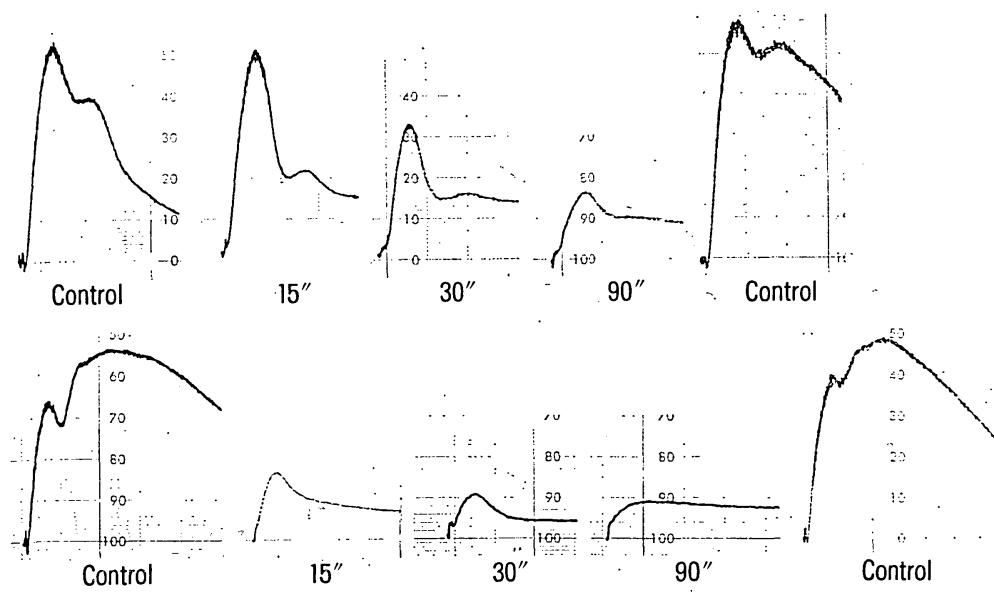

Fig. 8 CO-bubbling.

MPAs before the $\mathrm{O}_{2}$ inhalation.

On the other hand, the ischemia caused by arm ligations decreased the MPAs compared to the MPAs of preligation. These results contradict the previous explanations. But the following explanations will allow us to make a reasonable interpretation of the results.
In the chronic ischemic state, the MPA increased is caused by the movements of the platelets through the sclerotic vessel or by the deficiency of $\mathrm{O}_{2}$ for a long time. But in the acute ischemic state, the MPA is suppressed because by inhibiting platelet aggregability the homeostasis is kept. We were not able to find reports concerning those experiments. 


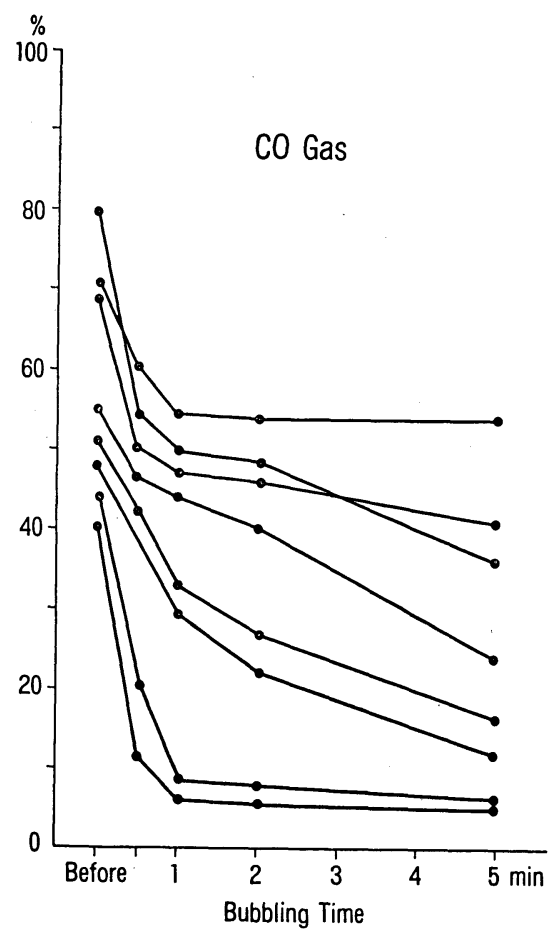

Fig. 9 The effect on ADP $(2 \mu \mathrm{M} / l)$ induced platelet aggregability by $\mathrm{CO}$ gas bubbling.

In vitro, although if the ischemic state is kept for the PRP by passing the $\mathrm{N}_{2}$ gas, the MPA does not significantly change. Thus, it suggests that the ischemic state in vivo causes various pathophysiology to the platelet aggregation.

In our other experiment, the $\mathrm{O}_{2}$ gas bubblings increased the MPA markedly. Although we cannot explain this mechanism, a possible explanation is that the $\mathrm{O}_{2}$ has radical electrons ${ }^{11-13)}$ which might excite the aggregation of the PRP. Furthermore, $\mathrm{O}_{2}$ also various unstable electrons such as the superoxide anion ${ }^{14-16)}$. These unstable electrons react with various lipids in the body, and they change the lipids to peroxides. ${ }^{17)}$ Consequently, these peroxides (for example, various prostanoids) might be the cause of the MPA increase.

The CO suppressed the MPA tremendously. As seen in other articles it is known that the $\mathrm{CO}$ combines with the $\mathrm{P} 450$ proteins ${ }^{18)}$ and together inhibit the electron transfer system. Therefore, it is speculated that the electron transfer system plays an important role in the development of the MPA. (Cinti ${ }^{19)}$ also reports that the CO inhibits collagen induced MPA.)
From these experiments we conclude that: if the electron transfer system is not kept in a normal condition for the chronic anoxia, the aggregation of PRP will be enhanced, but in an acute ischemic state, its normal electron transfer system will react for the regulation of platelet aggregation, namely as a suppression of the MPA. Finally, the complete disturbance of the electron transfer system will inhibit the platelet aggregation because of the lack of energy.

These results are very important in understanding the mechanisms of the platelet aggregation in ischemic diseases.

\section{References}

1) Prencipe, M., et al.: Platelet aggregation in cerebrovascular patients (edited by Agnoli, A. \& Fazio, C. Platelet aggregation in the Pathogenesis of cerebrovascular disorders), Springer-Verlag, Berlin, Heidelberg, New York, 1977, p. 129.

2) FitzGerald, G. A., et al.: Increased Prostacyclin biosynthessis in patients with severe atherosclerosis and platelet activation. New Engl. J. Med., 310: 1065 (1984).

3) Gryglewski, R. J., et al.: Treatment of ischaemic stroke with prostacyclin. Stroke, 14: 197 (1983).

4) Izawa, M., et al.: Potentiation of platelet aggregation induced by several kinds of aggregating agents -Platelet aggregabilities induced by the mixture of epinephrine and collagen in healthy persons and patients with effort angina-. J. Jpn. Atheroscler. Soc., 13: 89 (1985).

5) Kanazawa, T., et al.: A study on the mechanism of myocardial infarction-From view points of oxygen and platelet aggregation-. J. Jpn. Atheroscler. Soc., 14: 171 (1986).

6) Heyns, A. P., et al.: The inhibition of platelet aggregation by an aorta intima extract. Thrombos. Diathes. Haemorrh., 32: 417 (1974).

7) Green, L. H., et al.: Platelet activation during exercise-induced myocardial ischemia. New Engl. J. Med., 302: 193 (1980).

8) Satomura, K.: Hemodynamic responses, platelet functions, prostaglandin activities and catecholamine release during angina induced by stress testing. J. Jpn. Soc. Int. Med., 74: 287 (1985).

9) Awad, I., et al.: Treatment of acute focal cerebral ischemia with prostacyclin. Stroke, 14: 203 (1983).

10) Otsuki, Y., et al.: Platelet aggregability in cerebral thrombosis-Analyzed for vessel stenosis-. Stroke, 14: 368 (1983).

11) Bors, W., et al.: On the nature of biochemically generated hydroxyl radicals. Eur. J. Biochemi., 95: 62 (1979). 
A Study on the Changes of Platelet Aggregability Due to Ischemia

12) McCord, J. M. and Day, E. D.: Superoxidedependent production of hydroxyl radical catalysed by iron-EDTA complex. FEBS Lett., 86: 139 (1978).

13) Halliwell, B.: Superoxide-dependant formation of hydroxyl radicals in the presence of iron salts. FEBS Lett., 96: 238 (1978).

14) Lamora, A. A., et al.: Cholesterol hydroperoxide formation in red cell membranes and photohemolysis in erythropoietic protoporphyria. Science, 179: 1131 (1931).

15) Butler, J., et al.: The reaction between the superoxide anion radical and cytochrome C. Biochem. Biophys. Acta, 408: 215 (1975).
16) Kakinuma, K. and Minagami, S.: Affects of fatty acids on superoxide radical generation in leukocytes. Biochem. Biophys. Acta, 538: 50 (1978).

17) Sugioka, K. and Nakano, M.: A possible mechanism of the generation of singlet molecular oxygen in NAODH-dependent microsomal lipid peroxidation. Biochem. Biophys. Acta, 423: 203 (1976).

18) Makino, R. and Ishimura, Y.: Reaction mechanisms of cytochrome R-450. Metabolism and Disease, 19: 1747 (1982).

19) Cinti, D. L. and Feinstein, M. B.: Platelet cytochrome p-450: A possible role in arachidonateinduced aggregation. Biochem. Biophys. Res. Comm., 73: 171 (1976).

\section{Summary}

To clarify the mechanism of increasing platelet aggregation in ischemic diseases, the following experiments were carried out.

1) Maximum platelet aggregability (MPA) before and after $\mathrm{O}_{2}$ inhalation were estimated in 6 patients ( 2 a victim of strokes, 2 a victim of old myocardial infarctions, and 1 a victim of cor pulmonale, and 1 a victim of hypertensive) who were given $\mathrm{O}_{2}$ of $2 \mathrm{liter} / \mathrm{min}$ via nasal canal for dyspnea. After the $\mathrm{O}_{2}$ inhalation of 60 minutes, the ADP and epinephrine induced MPAs were suppressed compared to the MPAs before the inhalation. In the collagen induced MPAs of the same above condition, a decreasing trend was recognized.

2) The ADP induced and the epinephrine induced MPAs in the venous blood showed higher trends compared to the same two kinds of MPAs in the arterial blood, but in the collagen induced
MPA, there were no differences found (between the venous and the arterial blood). MPAs were measured in 6 patients; 3 of whom were victims of cerebral thrombosis, 2 of whom were victims of ischemic heart diseases, and 1 who suffered from hypertensive.

3) The MPAs in the ischemic blood (by arm ligation) were defined in 10 healthy persons. After the 5 minute ligations, the MPAs were suppressed.

4) After the $\mathrm{O}_{2}$ bubblings, the MPAs in 8 healthy persons increased.

After the $\mathrm{N}_{2}$ bubblings the MPAs did not change significantly, but after the $\mathrm{CO}$ bubblings, the MPAs decreased markedly.

Key words: Platelet aggregation in venous and arterial blood, $\mathrm{O}_{2}, \mathrm{~N}_{2}$ and $\mathrm{CO}$ bubbling to PRP, armligation (ischemia) and platelet aggregation, $\mathrm{O}_{2}$ inhalation and platelet aggregation. 